\title{
Medicago-Sinorhizobium-Ralstonia: A Model System to Investigate Pathogen-Triggered Inhibition of Nodulation
}

\author{
Claire Benezech, ${ }^{\dagger}$ Alexandre Le Scornet, and Benjamin Gourion \\ LIPM, Université de Toulouse, INRA, CNRS, 84195 Castanet-Tolosan, France \\ Accepted 17 February 2021.
}

\begin{abstract}
How plants deal with beneficial and pathogenic microorganisms and how they can tolerate beneficial ones and face pathogens at the same time are questions that remain puzzling to plant biologists. Legume plants are good models to explore those issues, as their interactions with nitrogen-fixing bacteria called rhizobia results in a drastic and easy-tofollow phenotype of nodulation. Intriguingly, despite massive and chronic infection, legume defense reactions are essentially suppressed during the whole symbiotic process, raising a question about a potential negative effect of plant immune responses on the establishment of nodulation. In the present study, we used the model legume, Medicago truncatula, coinoculated with mutualistic and phytopathogenic bacteria, Sinorhizobium medicae and Ralstonia solanacearum, respectively. We show that the presence of $R$. solanacearum drastically inhibits the nodulation process. The type III secretion system of $R$. solanacearum, which is important for the inhibition of pathogen-associated molecular pattern-triggered immunity (PTI), strongly contributes to inhibit nodulation. Thus, our results question the negative effect of PTI on nodulation. By including a pathogenic bacterium in the interaction system, our study provides a new angle to address the influence of the biotic environment on the nodulation process.
\end{abstract}

Keywords: coinoculation, legume, nitrogen-fixing bacteria, pathogen, symbiosis, tripartite system

Legumes can interact with nitrogen-fixing bacteria called rhizobia, which provide them nitrogen. These bacteria are hosted in root nodules. At the early stages of the interaction, defense reactions that are normally induced by microbes through the plant perception of microbial-associated molecular patterns (MAMPs) or effectors are suppressed or weak and transient. For instance, in the model legume Medicago truncatula, defense-related genes are transitorily upregulated upon interaction with Sinorhizobium spp. (Lohar et al. 2006), but then, there are no typical defense reactions all along the interaction (Benezech et al. 2020b). Interestingly,

${ }^{\dagger}$ Corresponding author: C. Benezech; claire_benezech@orange.fr

Funding: B. Gourion was supported by grants ANR-10-LABX-41 and ANR-17-CE20-0013 and the INRAE Département Santé des Plantes et Environnement.

The author(s) declare no conflict of interest.

(c) (1) () () Copyright () 2021 The Author(s). This is an open access article cc) 1 (1) these transient defense responses are strongly increased when Medicago spp. interact with a bacterial mutant altered in production of exopolysaccharide (EPS), a determinant known to suppress MAMP-triggered immunity (MTI) (Aslam et al. 2008; Jones et al. 2008). These observations raise a question about the influence of the biotic environment, including pathogens, on nodulation. In the past, this question was mostly addressed using systems devoid of pathogens, in which the presence of the aggressor was mimicked by treatment with MAMP (Lopez-Gomez et al. 2012) or in which the plant defense signaling pathways were artificially switched off (Stacey et al. 2006). Those molecular studies showed that plant defenses have an antagonistic effect on nodulation. However, other studies indicate an overlap of the plant response to MAMP and to nodulation signals (Serna-Sanz et al. 2011). Furthermore, boosting MTI through the constitutive expression of EFR, the receptor of the elf26 MAMP shared by bacterial pathogens and rhizobia (Berrabah et al. 2019), has no strong impact on nodulation (Pfeilmeier et al. 2019).

To evaluate whether the pathogen impacts the nodulation process, an in-vitro tripartite system involving $M$. truncatula (Pecrix et al. 2018), its symbiotic partner Sinorhizobium medicae WSM419 (Reeve et al. 2010), and the phytopathogenic bacterium Ralstonia solanacearum GMI1000 (Salanoubat et al. 2002) was set up. $R$. solanacearum has been known to trigger wilting symptoms on a non-nodulated $M$. truncatula A17 ecotype that is susceptible to $R$. solanacearum GMI1000 (Turner et al. 2009; Vailleau et al. 2007). $R$. solanacearum GMI1000 is a model soil pathogen that colonizes the xylem of its hosts. It displays a T3SS that allows the translocation of effector proteins (T3SEs) into the cells of its host. A total of 24 Ralstonia T3SEs were shown to inhibit MTI in Arabidopsis thaliana and in Nicotiana benthamiana (Landry et al. 2020), although this role has not yet been formally described in genus Medicago, in which GMI1000 effectors are crucial for pathogenicity (Vailleau et al. 2007). When efficient, this suppression of immunity is referred to as effector-triggered susceptibility (ETS) (Jones and Dangl 2006). On M. truncatula A17, despite development of plant defenses, $R$. solanacearum colonizes the nodules and roots (Benezech et al. 2020a), but the effect of this pathogen on $M$. truncatula nodulation has so-far not been described.

In our laboratory, the routine conditions used to study $R$. solanacearum $-M$. truncatula pathogenic interaction and nodulation differ only by temperature (Fahraeus solid medium [Fåhraeus 1957] at $28^{\circ} \mathrm{C}$ for interactions with $R$. solanacearum and at $25^{\circ} \mathrm{C}$ for nodulation). To determine whether temperatures adapted for pathogenic interaction might be used 
to evaluate the impact of $R$. solanacearum on nodulation, we first verified whether $M$. truncatula can nodulate at $28^{\circ} \mathrm{C}$ (Fig. 1). At both 14 and 21 days postinoculation (dpi), plants cultivated at $28^{\circ} \mathrm{C}$ display an average of one nodule per plant, while $25^{\circ} \mathrm{C}$ controls harbor two times as many nodules. These results indicate that, despite a negative impact of high temperature on the symbiotic process, $28^{\circ} \mathrm{C}$ is a temperature suitable to study the effect of $R$. solanacearum on Medicago nodulation.

Thus, $M$. truncatula seedlings were then coinoculated with both the pathogenic and the mutualistic bacteria at equal densities onto plants (optical density at $600 \mathrm{~nm}\left[\mathrm{OD}_{600}\right]=0.1$ in sterile distilled water), and the development of nodules was monitored for 28 days. S. medicae and $R$. solanacearum cells were cultivated overnight in, respectively, tryptone yeast (Beringer 1974) and Phi medium (Poueymiro et al. 2009). While on control plants, inoculated only with the rhizobium, nodules were observable from day 14 and continued to develop continuously until the last point analyzed (28 dpi) (Fig. 2A), we were not able to detect any nodules on coinoculated plants during the whole experiment (Fig. 2B). Plant age and nutritional status can affect, respectively, plant susceptibility to pathogens and interaction with rhizobia (Campisi and Robert 2014). For this reason, we also analyzed the influence of $R$. solanacearum on nodulation with older plants in which the nitrogen storage in cotyledons was already reduced (11-day-old seedlings). No nodules were formed in those coinoculated plants (Fig. 2D). In contrast, in seedlings inoculated only with $S$. medicae, the nodule number increased over the time (Fig. 2D). At $28 \mathrm{dpi}$, for plants that were inoculated when they were 0 and 11 days old, two nodules per plant were present in average on 34 control plants, but none were detected on 34 coinoculated plants (Fig. 2D). These results indicate that the presence of the phytopathogenic bacterium interferes drastically and early with nodulation (independently of the nitrogen need of the plants).

To evaluate whether $R$. solanacearum-mediated inhibition of nodulation is dose-dependent and potentially due to direct antagonism with $S$. medicae or to root congestion by

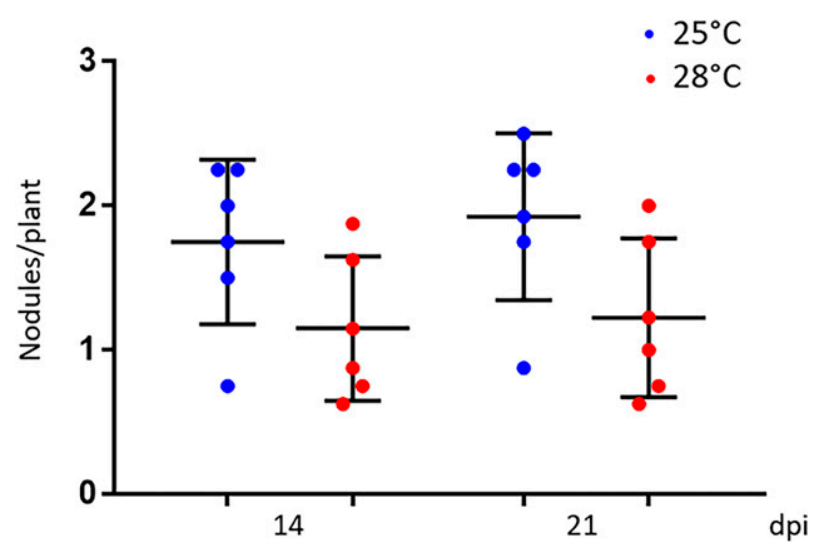

Fig. 1. Temperature impacts Medicago truncatula nodule development Medicago truncatula A17 inoculated with Sinorhizobium medicae WSM419 cultivated under the standard nodulation condition $\left(25^{\circ} \mathrm{C}\right)$ or a condition adapted to study Medicago truncatula-Ralstonia solanacearum interaction $\left(28^{\circ} \mathrm{C}\right)$. The number of nodules is lower when plants were grown at $28^{\circ} \mathrm{C}$. A Kruskal-Wallis test was performed, followed by a Wilcoxon test at 14 days postinoculation (dpi) and 21 dpi $(P$ value $>$ 0.05 ). Experiments were replicated two times on 40 plants per condition and for each biological replication.
$R$. solanacearum, the same experiment was performed with ten times fewer cells of $R$. solanacearum. In such a condition, as when the two microorganisms were inoculated at equal densities, no nodules developed on coinoculated plants (Fig. 2D), suggesting that nodulation inhibition is not due to competition for the access to the infection site.

Because of its key role in the subversion of plant cell physiology, we evaluated the importance of $R$. solanacearum T3SS in the inhibition of nodulation. Seedlings were coinoculated with $S$. medicae and the hrcV mutant of $R$. solanacearum, deficient for the T3SS (Cunnac et al. 2004). Root tip browning was observed on seedlings coinoculated with $S$. medicae and the $R$. solanacearum wild-type strain (WT), which can be due to the appearance of disease (ETS) or the development of defense responses (effector-triggered immunity-like) (Fig. 2E). In contrast, no such a symptom was detectable when plants were coinoculated with $S$. medicae and the $h r c V$ mutant (Fig. 2F). On those plants, nodules were frequently observed (Fig. 2C). However, the Ralstonia T3SS mutant still has the ability to partially inhibit nodulation by $S$. medicae (Fig. 2D). The effect was not significantly different when the disarmed pathogen was inoculated at reduced density and a similar tendency was observed for plants inoculated immediately after transfer on Fahreus medium. Indeed, from $28 \mathrm{dpi}$, regardless the age of seedlings and the densities of $R$. solanacearum inoculum $\left(\mathrm{OD}_{600}=\right.$ 0.1 or 0.01 ), on average, less than one nodule per plant was present on 34 coinoculated plants (Fig. 2D). Thus, our results indicate that $R$. solanacearum T3SS strongly contributes to the inhibition of nodulation.

Our data reinforces the idea that the biotic environment can impact the nodulation process. Legume-rhizobia interactions are most often studied with experimental systems restricted to the two symbiotic partners. However, such a reductionist approach is far from the complex reality of natural environments and it is important to develop experimental systems including one or more additional microbial partners to understand the complexity of the interactions. We took a first step in this direction that allows evaluating how other interactions can influence nodulation efficiency. We observed that WT $R$. solanacearum totally inhibits nodulation, perhaps through defense response elicitation (although A17 is susceptible to GMI1000). In contrast, the hrcV mutant does not totally block nodulation (Fig. 3B). This partial inhibition of nodulation might be due to induction of defense responses that are not counteracted by an effector normally translocated through $R$. solanacearum T3SS. Among the factors potentially triggering defense responses are, notably, surface components acting as MAMPs and ethylene produced by Ralstonia spp. Indeed, ethylene is both a defense response elicitor and an inhibitor of nodulation in Medicago spp. (Oldroyd et al. 2001; Peters and Crist-Estes 1989; Valls et al. 2006). Other $R$. solanacearum factors as well as rhizobial determinants, such as the nod factors, EPS, and 1-aminocyclopropane-1-carboxylate deaminase (that might reduce ethylene production by degrading the ethylene precursor), could contribute to the suppression of defense responses induced by the disarmed pathogen. In addition, WSM419 strain possesses a T4SS that might also play such a role (Fig. 3C). Whether the reduced inhibitory effect of the $h r c V$ mutant on nodulation reflects an inability of PTI to prevent nodule development in our system or whether the rhizobium or the $h r c V$ mutant are able to suppress PTI induced by the $R$. solanacearum mutant remains to be determined (Fig. 3). 


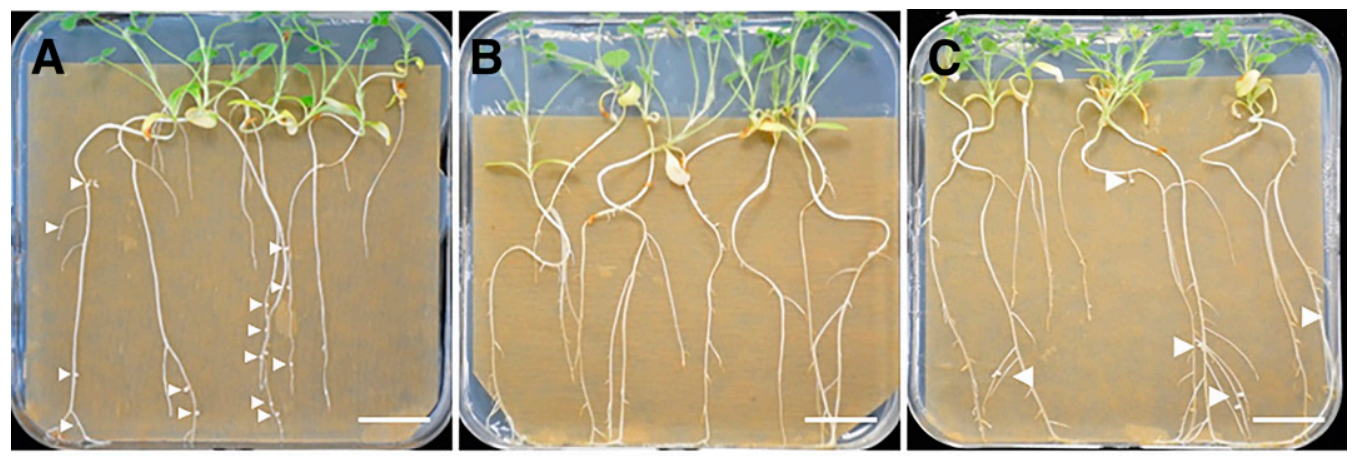

D

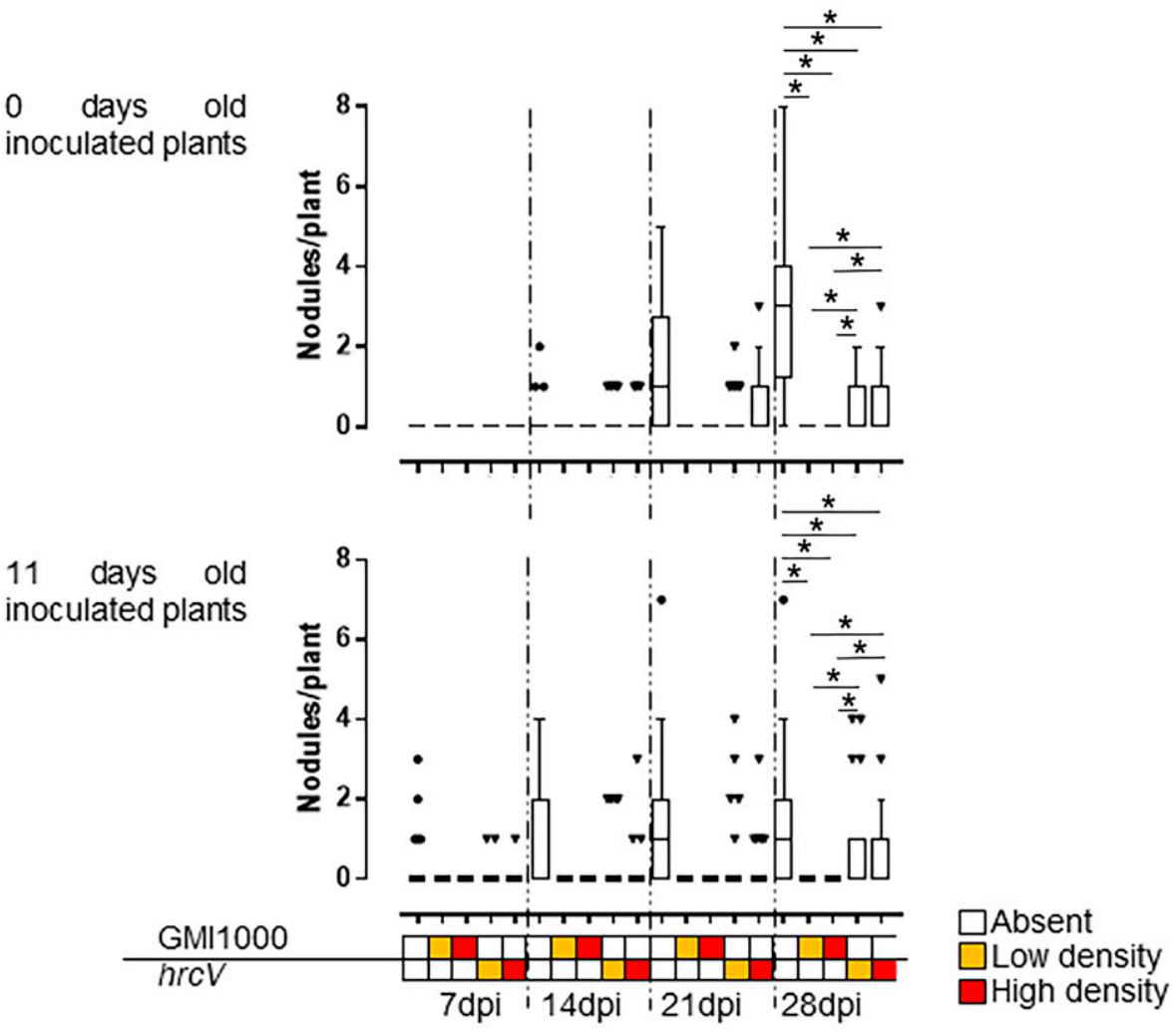

$\mathbf{E}$

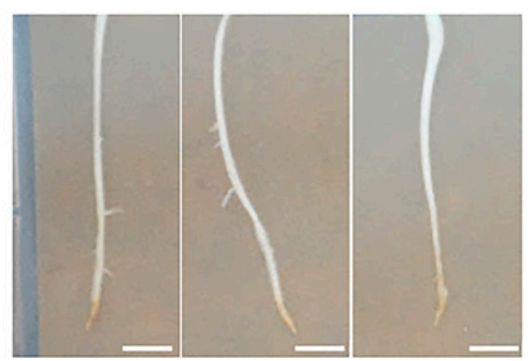

$\mathbf{F}$

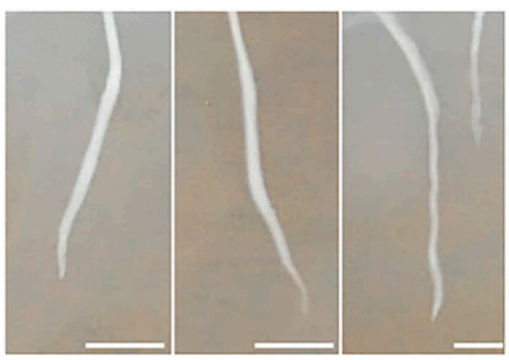

Fig. 2. Inhibition of Medicago truncatula nodulation by Ralstonia solanacearum relies on the pathogen type III secretion system (T3SS). A, Medicago truncatula A17 inoculated with Sinorhizobium medicae WSM419 at 28 days postinoculation (dpi). B, M. truncatula coinoculated with S. medicae WSM419 and Ralstonia solanacearum GMI1000 wild-type (WT) strain at 28 dpi. C, M. truncatula coinoculated with strain WSM419 and the hrcV mutant of $R$. solanacearum altered in the T3SS at 28 dpi. M. truncatula A17 developed nodules upon inoculation with S. medicae WSM419 (A) and upon coinoculation with the $h r c V$ mutant of $R$. solanacearum (C). No nodules were observed when M. truncatula was coinoculated with S. medicae WSM419 and $R$. solanacearum GMI1000 WT strains (B). Bars $=2 \mathrm{~cm}$. White arrows indicate nodules. D, Monitoring of nodule numbers by plants inoculated or coinoculated as described above when they are 0 and 11 days old according to the pathogen density during a kinetic experiment. A Kruskal-Wallis test was performed followed by a Wilcoxon test at $28 \mathrm{dpi}$ (asterisks $\left(^{*}\right)$ indicate $P$ value $<0.05$ ). Experiments were replicated three times on 32 plants per condition and for each biological replication. E, Roots of $M$. truncatula coinoculated with $S$. medicae WSM419 WT strain and $R$. solanacearum GMI1000 WT strain at 7 dpi. F, M. truncatula coinoculated with $S$. medicae WSM419 WT strain and the mutant hrcV of $R$. solanacearum GMI1000 strain, at $7 \mathrm{dpi}$. Browning root tips were observed when plants were inoculated with $R$. solanacearum GMI1000 WT strain but are not observed upon inoculation with the mutant $h r c V$ of $R$. solanacearum GMI1000 strain. Bars $=5 \mathrm{~mm}$. 


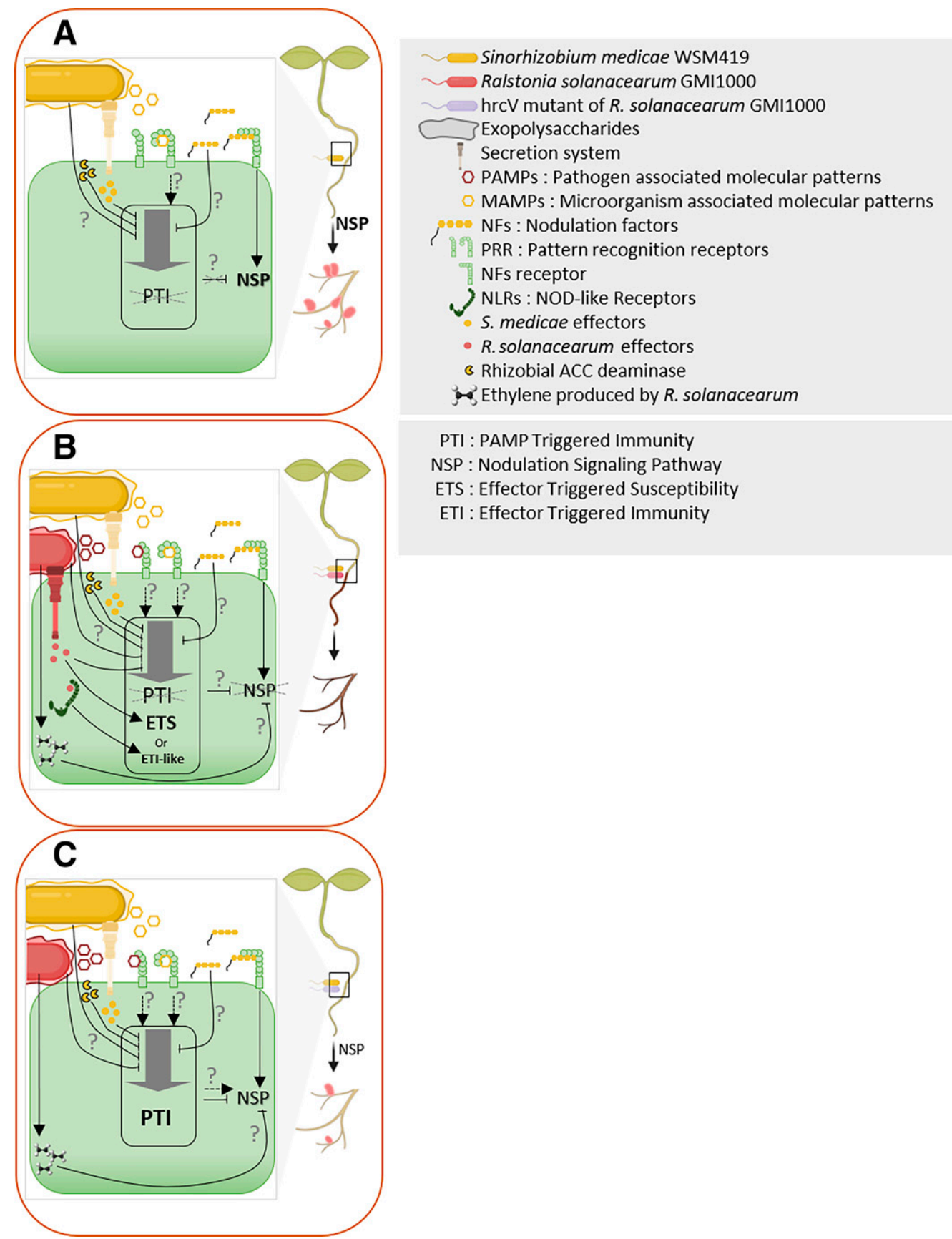

Fig. 3. Hypothetical model of Ralstonia-mediated inhibition of Medicago nodulation. A, Absence of pathogen. Pathogen-associated molecular pattern-triggered immunity (PTI) is presumed to be transiently and moderately activated (Jones et al. 2008; Lohar et al. 2006), which allows nodulation. B, R. solanacearum represses PTI through effector-triggered susceptibility (ETS) or $R$. solanacearum effectors are recognized by Nod-like receptors (NLR), which induces defense responses (effector-triggered immunity-like) and no nodulation is observed. C, The hrcV disarmed mutant of $R$. solanacearum is not able to translocate the effector that would inhibit PTI. Nevertheless, nodulation is not totally abolished, giving rise to two hypotheses: i) PTI does not have the potential to inhibit nodulation or ii) one or more rhizobial or $R$. solanacearum determinants, such as Nod factors or effectors, suppress PTI and allow nodulation.

\section{LITERATURE CITED}

Aslam, S. N., Newman, M.-A., Erbs, G., Morrissey, K. L., Chinchilla, D., Boller, T., Jensen, T. T., De Castro, C., Ierano, T., Molinaro, A., Jackson, R. W., Knight, M. R., and Cooper, R. M. 2008. Bacterial polysaccharides suppress induced innate immunity by calcium chelation. Curr. Biol. 18:1078-1083.

Benezech, C., Berrabah, F., Jardinaud, M.-F., Le Scornet, A., Milhes, M., Jiang, G., George, J., Ratet, P., Vailleau, F., and Gourion, B. 2020a. Medicago-Sinorhizobium-Ralstonia co-infection reveals legume nodules as pathogen confined infection sites developing weak defenses. Curr. Biol. 30:351-358.e4.
Benezech, C., Doudement, M., and Gourion, B. 2020b. Legumes tolerance to rhizobia is not always observed and not always deserved. Cell. Microbiol. 22:e13124.

Beringer, J. E. 1974. R factor transfer in Rhizobium leguminosarum. Microbiology 84:188-198.

Berrabah, F., Ratet, P., and Gourion, B. 2019. Legume nodules: Massive infection in the absence of defense induction. Mol. Plant-Microbe Interact. 32:35-44.

Campisi, J., and Robert, L. 2014. Cell senescence: role in aging and agerelated diseases. Pages 45-61 in: Interdisciplinary Topics in Gerontology. L. Robert, and T. Fulop, eds. S. Karger AG, Basel. 
Cunnac, S., Occhialini, A., Barberis, P., Boucher, C., and Genin, S. 2004. Inventory and functional analysis of the large Hrp regulon in Ralstonia solanacearum: Identification of novel effector proteins translocated to plant host cells through the type III secretion system. Mol. Microbiol. 53:115-128.

Fåhraeus, G. 1957. The Infection of clover root hairs by nodule bacteria studied by a simple glass slide technique. Microbiology 16:374-381.

Jones, J. D. G., and Dangl, J. L. 2006. The plant immune system. Nature 444:323-329.

Jones, K. M., Sharopova, N., Lohar, D. P., Zhang, J. Q., VandenBosch, K. A., and Walker, G. C. 2008. Differential response of the plant Medicago truncatula to its symbiont Sinorhizobium meliloti or an exopolysaccharide-deficient mutant. Proc. Natl. Acad. Sci. 105:704-709.

Landry, D., González-Fuente, M., Deslandes, L., and Peeters, N. 2020. The large, diverse, and robust arsenal of Ralstonia solanacearum type III effectors and their in planta functions. Mol. Plant Pathol. 21:13771388.

Lohar, D. P., Sharopova, N., Endre, G., Peñuela, S., Samac, D., Town, C., Silverstein, K. A. T., and VandenBosch, K. A. 2006. Transcript analysis of early nodulation events in Medicago truncatula. Plant Physiol. 140:221-234.

Lopez-Gomez, M., Sandal, N., Stougaard, J., and Boller, T. 2012. Interplay of flg22-induced defence responses and nodulation in Lotus japonicus. J. Exp. Bot. 63:393-401.

Oldroyd, G. E. D., Engstrom, E. M., and Long, S. R. 2001. Ethylene inhibits the Nod factor signal transduction pathway of Medicago truncatula. Plant Cell 13:1835-1849.

Pecrix, Y., Staton, S. E., Sallet, E., Lelandais-Brière, C., Moreau, S., Carrère, S., Blein, T., Jardinaud, M.-F., Latrasse, D., Zouine, M., Zahm, M., Kreplak, J., Mayjonade, B., Satgé, C., Perez, M., Cauet, S., Marande, W., Chantry-Darmon, C., Lopez-Roques, C., Bouchez, O., Bérard, A., Debellé, F., Muños, S., Bendahmane, A., Bergès, H., Niebel, A., Buitink, J., Frugier, F., Benhamed, M., Crespi, M., Gouzy, J., and Gamas, P. 2018. Whole-genome landscape of Medicago truncatula symbiotic genes. Nat. Plants 4:1017-1025.

Peters, N. K., and Crist-Estes, D. K. 1989. Nodule formation is stimulated by the ethylene inhibitor aminoethoxyvinylglycine. Plant Physiol. 91:690-693.

Pfeilmeier, S., George, J., Morel, A., Roy, S., Smoker, M., Stransfeld, L., Downie, J. A., Peeters, N., Malone, J. G., and Zipfel, C. 2019. Expression of the Arabidopsis thaliana immune receptor EFR in Medicago truncatula reduces infection by a root pathogenic bacterium, but not nitrogen-fixing rhizobial symbiosis. Plant Biotechnol. J. 17:569-579.

Poueymiro, M., Cunnac, S., Barberis, P., Deslandes, L., Peeters, N., Cazale-Noel, A.-C., Boucher, C., and Genin, S. 2009. Two type III secretion system effectors from Ralstonia solanacearum GMI1000 determine host-range specificity on tobacco. Mol. Plant-Microbe Interact. 22:538-550.

Reeve, W., Chain, P., O’Hara, G., Ardley, J., Nandesena, K., Bräu, L., Tiwari, R., Malfatti, S., Kiss, H., Lapidus, A., Copeland, A., Nolan, M., Land, M., Hauser, L., Chang, Y.-J., Ivanova, N., Mavromatis, K., Markowitz, V., Kyrpides, N., Gollagher, N., Yates, R., Dilworth, M., and Howieson, J., 2010. Complete genome sequence of the Medicago microsymbiont Ensifer (Sinorhizobium) medicae strain WSM419. Stand. Genomic Sci. 2:77-86.

Salanoubat, M., Genin, S., Artiguenave, F., Gouzy, J., Mangenot, S., Arlat, M., Billault, A., Brottier, P., Camus, J. C., Cattolico, L., Chandler, M., Choisne, N., Claudel-Renard, C., Cunnac, S., Demange, N., Gaspin, C., Lavie, M., Moisan, A., Robert, C., Saurin, W., Schiex, T., Siguier, P., Thébault, P., Whalen, M., Wincker, P., Levy, M., Weissenbach, J., and Boucher, C. A. 2002. Genome sequence of the plant pathogen Ralstonia solanacearum. Nature 415:497-502.

Serna-Sanz, A., Parniske, M., and Peck, S. C. 2011. Phosphoproteome analysis of Lotus japonicus roots reveals shared and distinct components of symbiosis and defense. Mol. Plant-Microbe Interact. 24:932937.

Stacey, G., McAlvin, C. B., Kim, S.-Y., Olivares, J., and Soto, M. J. 2006. Effects of endogenous salicylic acid on nodulation in the model legumes Lotus japonicus and Medicago truncatula. Plant Physiol. 141: 1473-1481.

Turner, M., Jauneau, A., Genin, S., Tavella, M.-J., Vailleau, F., Gentzbittel, L., and Jardinaud, M.-F. 2009. Dissection of bacterial wilt on Medicago truncatula revealed two type III secretion system effectors acting on root infection process and disease development. Plant Physiol. 150:1713-1722.

Vailleau, F., Sartorel, E., Jardinaud, M.-F., Chardon, F., Genin, S., Huguet, T., Gentzbittel, L., and Petitprez, M. 2007. Characterization of the interaction between the bacterial wilt pathogen Ralstonia solanacearum and the model legume plant Medicago truncatula. Mol. Plant-Microbe Interact. 20:159-167.

Valls, M., Genin, S., and Boucher, C. 2006. Integrated regulation of the type III secretion system and other virulence determinants in Ralstonia solanacearum. PLoS Pathog. 2:e82. 